\author{
Henryk Zielaskiewicz \\ Dyrektor Biura Logistyki PKP S.A. \\ Akademia WSB w Dąbrowie Górniczej
}

DOI: 10.35117/A_ENG_21_06-07-08_01

\title{
Innovative solutions in container transport
}

\begin{abstract}
The article presents a historical perspective on the development of transport technology, i.e. a container. It was indicated what solutions are currently used on terminals in order to shorten the service time of intermodal units and ensure an increase in the efficiency of handling operations. Intelligent containers are presented, which are equipped with numerous sensors, which include can follow the route of the container. The author outlined what activities are currently carried out by governmental and international organizations to ensure cargo safety during transport operations. The directions of changes in the design of containers and IT support systems have been signaled, and how the logistics industry reacts and should proceed in the era of the spread of the coronavirus in the event that many companies' strategies will be revised with new consumer behavior.
\end{abstract}

Keywords: Intermodal transport; Intelligent containers; Information systems; Coronovirus CoVid

\section{Introduction}

In the global economy recovering from losses, the production of goods developed in various regions of the world, after the crisis in 2009. Labour costs and the ability to quickly prepare staff for the implementation of new technologies were important elements in the selection of the production site. The development of new technologies, both in the sphere of production and services, has also become the elements of the changes taking place. New information technologies are developing very quickly. Data and information transformed in computers into knowledge resources have become an important element in the development of new technologies, but also in winning new markets. Changes in the exchange of information and its use, and thus information management, enable the construction of new areas of production and services. The acquired knowledge becomes productive, so it brings specific profits when it is used at the right time and in a specific case. Changes taking place in the field of production of goods and the opening of new markets shape the flows of cargo and affect the development of logistics services. Logistics services in the field of goods movement are one of the basic elements of all production and consumption processes that create the effect of economic development. New technologies in the processes of moving raw materials and goods contribute to building more and more efficient supply chains while reducing the costs of logistics services. Transport processes, which constitute about $70 \%$ of all activities in logistics, should be improved both in the area of applying new technologies and organizing supply chains. Intermodal transport has been developed in cargo transportation since the last decade of the last century. Unified transport units such as containers have introduced significant changes in transport processes. In the initial period, only sea transport was carried out using this system. Cargo transport in containers developed slowly and was dedicated to the transport of a small segment of cargo. The first container ship was the vessel "Ideal X". In 1956, he sailed from Newark to Hudson with a cargo of 58 containers. In 1966, the first container ship reached Europe. It was a "Fairgrand" and entered the port of Bremen with a cargo of 226 containers. Gradually, an increasing generic range of loads was covered, and the structures of load units were also changed. But the handling technology itself and the design requirements for some 
parameters are standardized and have not been changed for years. Along with new cargo segments, including those of high value or those that may pose a threat to the environment, and the development of IT technologies, the container structures are also constantly improved. Security systems for the transported cargo and monitoring of the route of transport routes are more and more widely used. Currently used technical security measures are extremely important for ensuring safety in the transport of containers. The most common are the so-called non-invasive inspection methods, i.e. scanning containers with gamma rays, X-rays or nerve bundle, gates or scanners of fixed or mobile construction. However, the development of information technology allows for the improvement of supply chains and makes them transparent and secure. "Smart" containers and electronic container seals are gaining more and more recognition. Modern transport solutions are particularly important in the logistics of highly processed goods, which most often have high commercial value. The basic criteria for selecting a transport service are then its quality, safety of goods and reliability. Ensuring the safety of transport also means a fast flow of information, but also the security of the information itself. In inland intermodal transport, standardized information systems have not yet developed. The main weaknesses of information systems in this transport segment include: incompatibility of information systems at the international and national level (intermodal operators use different and at the same time separate information systems), railway carriers, intermodal operators and terminal operators (who also organize transport for the so-called last mile) are not "electronically" connected with sea and inland waterway operators, no uniform systems of electronic information about shipments and trains (e.g. tracking and tracing). These systems should provide real-time information to customers about the intermodal unit. Providing universal character and compatibility will facilitate data sharing and identification of companies responsible for transport problems. The implementation of modern information technologies in the intermodal transport sector should be an element of the strategy of creating a network of land intermodal terminals integrated with port terminals in Poland. An important issue is also the automation of transhipment processes, ensuring the necessity to shorten the service time of intermodal units at terminals and increase the efficiency of their service. More and more often, terminals are implementing highly automated and computer-controlled subsystems of intermodal unit transhipment from one means of transport to another. Projects aimed at improving the subsystems of unit service with the use of innovative information and telemetry solutions are implemented. Thanks to innovative information technologies, it should be possible to implement a unified system of charges for the use of transport infrastructure (both linear and point-based) in all EU Member States. An example of new solutions in intermodal units are: "Smart" containers - this name is used to describe a group of containers equipped with a transport route tracking system and various sensors. Not all containers are equipped with devices at the same level of "intelligence", some are even able to monitor the conditions of transport (for example, tilting, opening the door of the container each time, the atmosphere inside the container, information about people contacting the container is also collected) and signalling each attempt getting into the container by an unauthorized person or deterioration of transport conditions. Tank containers are equipped with several sensors ( 5 types on average) that control, for example, pressure, temperature, location, uncontrolled violation of the container door or tank valves. Data from these sensors based on telematics technologies are sent to the transport operator or to the appropriate services. Such solutions include the wireless TREC (Tamper-Resistant Embedded Controller) device or the Schenker smartbox, where GPS sensors are combined with RFID technology (Radio Frequency Identification, i.e. a method of identification using the frequency of the radio signal). A good example of the use of information systems in the so-called Smart containers is a system used on the French container ship CMA CGM Boganville, built in 2015 by Samsung Heavy Industries for CMA CGM. It was the largest container ship in the world at the time of its launch in August 2015, with a maximum capacity 
of 18,000 TEU. Intelligent containers cooperating with the central computer on this ship are equipped with sensor sensors that record time, humidity, vibration, impacts and attempts to theft. It is important because the container ship has the ability to transport a large number of containers equipped with refrigeration units. The ship is therefore adapted to the transport of large batches of goods sensitive to external factors, it has as many as 1,200 positions enabling connection to the power supply. Data from intermodal units are sent to the ship's service, and then to the transport operator, and can be sent to insurance companies and customs offices. Innovative solutions for containers are not only new technologies in the field of IT but also the use of lightweight composite materials. The universal 40-foot container, made using the classic method, weighs from 4 to 7 tons. Reducing the weight of the container allows you to transport a larger batch of cargo. The gross weight of the container is important, among others, due to the permissible axle loads on the road or rail, depending on the mode of transport.

Regardless of the technical and technological safeguards, legal and organizational safeguards are important in the container transport process.

An important issue in ensuring the safety of cargo in transport and logistics is the cooperation of companies related to the process of building supply chains on a global scale. Work on the organization and coordination of cargo security measures and preventive measures are carried out at various levels of government and international organizations and organizations associating companies from the TSL industry, and their effects include the following initiatives.

\section{CSI (Container Security Initiative)}

Container Safety Initiative - created by the US customs authorities in 2002 in order to protect international exchange flows between ports from which containers are shipped to the USA. The initiative takes the form of a bilateral agreement between US customs and the country's customs administration. Countries threatened by terrorism mainly participate in the initiative.

Specific CSI procedures, consisting of four main modules, help in detecting high-risk containers:

1. Use of electronic information to identify and trace containers that may pose an increased risk.

2. The use of technology that enables fast scanning of the container.

3. X-raying (ultrawaves) of containers at the port of loading.

4. The use of the so-called "Smart" containers.

\section{ISPS (International Ship and Part Facility Security Code)}

The International Ship and Port Facility Security Code has been in force in the world since 2004. The regulations created the basis for mutual cooperation between port managers, ship owners and state administration aimed at minimizing the threat of acts of terrorism.

\section{C - TPAT (Custom Trade Partnership Against Terrorism)}

Launched in 2002, cooperation and partnership of the trade and customs industry against terrorism. It is a joint effort by the US customs administration and economic zones to provide supply chains with the highest protection against terrorist activity. Joining the program is voluntary, but the company that chooses to do so is obliged to comprehensively control its supply network and cargo transport processes in accordance with the established criteria, providing the information required by the customs administration, in return for which it benefits from faster customs clearance and a number of amenities.

\section{4 - Hour Rule (24 Hour Advance Vessel Manifest Rule in the USA; 24 Hour Advance} Commercial Information Rule in Canada) 
The 24-hour rule - a system requiring the 24-hour notice prior to loading of a container sent to the USA or Canada, the customs administration of these countries, which makes the final decision on the approval of the container for loading. Any inconsistencies, such as entering the "Said to container" clause in the bill of lading, are unacceptable and prevent the container from being loaded onto the ship.

\section{AEO (Authorized Economic Operator)}

The program, in force in the European Union since January 1, 2008, is a response to the American C-TPAT, granting the status of an "authorized entrepreneur" to companies that meet certain security requirements.

The AEO status confirms that the company meets all security requirements, and the entrepreneur who has it can count on the reduction of the negative effects of increased customs controls on trade in goods and use simplified customs procedures. The legal basis for the functioning of the AEO is the Community Customs Code. A similar program is also being introduced by the Australian Customs Administration.

\section{STP (Secure Trade Partnership)}

Introduced in July 2006 as part of the national supply chain protection program in Singapore, taking into account the special role of the port of Singapore in global maritime trade (the largest container hub in the world).

In the entire supply chain, such extensive security procedures occur only in sea and air transport, and they are unified on a global scale. However, to be able to speak of complete safety, it becomes necessary to look at not only through the prism of individual modes of transport, but through the supply chain as a whole. One can risk a statement that the supply chain is as secure as its weakest link is reliable. When applying security systems, we must keep quality standards in mind, as well as ensure the efficient flow of goods and information about them, and thus the effectiveness of supply chains. Professional transport of loads using various modes of transport requires provisions and legal regulations thanks to which it will be safe for both the transported load and the surroundings of transport routes.

Containers undergo various modifications and new constructions are a response to the needs of shipping companies and the market. The big problem in terms of costs was the handling of unidirectional flows of cargo. After the cargo was transported in the container, it returned empty. Universal folding containers (4 FOLD) solve this problem to a large extent.

This type of solution offers, among others, the following savings:

- possibility of transporting four empty containers simultaneously on a wagon or car,

- reduction of space for storing empty containers in the yard/warehouse by up to $75 \%$,

- shorter time needed at the port to load empty containers (higher punctuality, loading time),

- possibility to lift four units with one crane (in the case of double cranes - eight units),

- making free space around ports by reducing space for storing empty containers near residential areas.

Autonomous container transporters at large terminals, e.g. port terminals, are certainly innovative solutions. They are equipped with electric drives and controlled by a central computer. Such solutions have been functioning for several years in the port of Hamburg. Port container terminals in Hamburg are also considering the use of drones to transport containers between terminals located at different quays. In Hamburg, the concept of such a drone is prepared in cooperation with the Frauenhofer Institute's Maritime Logistics Center. Transporting containers by drones would not take place inside the terminal, because cranes and AGVs are used for this type of operation. Drones would be used when a container needs to be transported from one terminal to another. This solution may in the future avoid traffic jams. In 
some ports, the transfer from one terminal to another, in the same port, passes through the urban agglomeration. Due to the fact that port areas are relatively expensive due to their business attractiveness and container terminals occupy large areas (very often they are built on a special pier built in the sea), which generates high costs. An alternative to such a solution can be fully automated container warehouses "TEUSTACK". The principle is similar to fully automatic pallet warehouses. If we have automated warehouses for load units such as pallets, why not load unit warehouses such as containers? The structure of such a warehouse must be of adequate strength as the weight of the container is several dozen tons. The containers will be stored in "racks" with a height of several layers. Such magazines as a pilot are already being built in the USA.

\section{Organizational changes after the crisis}

The current crisis caused by the virus pandemic will have a big impact on the global economy. It affects the continuity of production, paralyzes trade and has a negative impact on logistics processes. However, as usual, after the crisis, new areas of production and services are activated. Many companies introduce new innovative solutions. The new conditions contributed to the development of e-commerce.

The online sales market in Poland is developing well and its value is estimated at over PLN 50 billion. The coronavirus crisis will further strengthen this trade sector. After the crisis, the flows of loads and their directions will certainly change. The offer of logistics operators must adapt to the new conditions. More and more logistics operators will expand their services in servicing the e-commerce market. Many of these companies will treat the e-commerce sector as their core business. The development of e-commerce, which is growing year by year, has become something natural. During the period of quarantine and certainly after its abolition, it will strengthen its position, the more that in Poland it is still low compared to the European average. The countries that lead in this business are Great Britain and Germany. New communication technologies favour the development of this type of service. Serving this market requires sending a large number of individual shipments of various sizes. On this market, the PKP Group may also develop its activity in the field of transporting parcels by rail transport and by participating in projects for the construction of e-commerce warehouses in large cities using the land owned by PKP S.A. Depending on the size of the stream, shipments can be transported by PKP Intercity or PKP Cargo. "Internet" logistics requires specialized solutions and building supply chains that guarantee timely deliveries, which affects the quality of services provided. Logistics services in this segment bring more benefits to the larger scale of the business. A dedicated network of permanent intermodal train connections for this type of transport may prove to be a good solution. Sorting warehouses could be established at the terminals. Another direction for the development of intermodal transport could be the "Internet of Things". The development of transport in this technology is only in the sphere of ideas, it still requires a lot of technical and organizational solutions.

\section{Source materials}

[1] Giermański J. „Topping the Potential of Smart Containers”, Supply Chain Management Review, January/ February 2008, www.scm.com.

[2] Henryk Zielaskiewicz, Mirosław Antonowicz." Konteneryzacja w Logistyce Materiałów Niebezpiecznych" — Radom 2019

[3] https://www.wnp.pl/wiadomosci/innowacyjne-rozwiazania-w-transporcie-intermodalnymcz-2,-5806.html 